\title{
Traditional versus online newspapers: The perspective of news audiences in Botswana
}

\author{
William Lesitaokana, University of Botswana
}

Eno Akpabio, University of Namibia

Contemporary studies of journalism and new media indicate that news audiences prefer to read online newspapers because they are generally interactive, host multimedia content and report breaking news. However, the literature on the impact of digital media technologies on traditional print publication consumption patterns in Botswana and the African continent is hard to come by. Thus, this study, using multistage cluster sampling and focus group discussions, sets out to explore how audience members in Botswana engage with online news vis-á-vis traditional newspapers. It finds out that news audiences have a favorable attitude towards online newspapers but still prefer traditional newspapers, and that in Botswana specifically, access to online and traditional newspapers is influenced by factors such as cost and convenience. The study's findings indicate clearly that while new media technologies continue to influence new trends and practices in journalism globally, audiences' experience with these technologies differ from country to country.

Keywords: Botswana; attitude; journalism; audience members; online newspapers; traditional newspapers 
Undoubtedly, journalism, particularly the printed press, has been impacted by new digital media technologies. Scholars have underlined the need to study this impact that has resulted in a dramatic shift from 'traditional' to 'online' or 'convergence' journalism (Cottle 2000; Deuze 1999; Kawamoto 2003; Kolodzy 2006). Consequently, there are many theoretical and empirical studies that focus on the changes in newsroom structures (Davis 2000; Pavlik 2000); the shift in journalists' roles and practices (Fahy and Nisbet 2011; Granado 2011) and the increasing connection and engagement between newsrooms and news audiences (Lowrey 2006; Matheson 2004; Pavlik 2000). Other studies have focused on modern audiences' news consumption styles (Ahlers 2006; Thorson 2008).

Atton and Mabweazara (2011: 670) posit that while much research on new media and journalism is being undertaken in economically developed countries, only a few studies have been undertaken in Africa, hence, they call for a connection of 'accounts of journalism in Africa with Western research'. This, of course, is a tall order considering the depth and breadth of Western research on digital journalism. Also, there has been much debate as to whether the Internet qualifies as a new medium or a better outlet for news; but it appears that, for now, it supplements and complements traditional journalism (Scott 2005).

What is unclear in all the euphoria and dystopia about online journalism is how it compares with its print counterpart from the standpoint of audience members. More so in Africa, where traditional journalism seems to be carrying on as if the online threat that has sounded the death knell for many traditional newspapers in the West does not exist. In providing a case study of Botswana, the present study set out to compare audience members' disposition towards traditional print and online newspapers.

\section{Traditional newspapers in Botswana}

In Botswana, traditional newspapers have a long colonial history, dating to as far back as 1850 s. ${ }^{1}$ However, print publications, which included newsletters and newspapers, only became very popular during the lead up to Botswana's independence in the 1960s (Rantao 1996). According to Rantao (1996), these were useful for communicating electoral information and political messages, from both the British colonial government and the political parties in Bechuanaland at that time, to Botswana citizens in several dispersed communities within the country.

Later on, a number of professionally edited newspapers appeared, including Mmegi, the Botswana Guardian, the Botswana Gazette, the Botswana Daily News, Sunday Standard, The Voice, the Midweek Sun and many others. Conceivably, the introduction of these newspapers was necessitated by the growth in population and rise in literacy levels among the citizens following Botswana's independence in 1966. Of all the newspapers in Botswana, the Daily News is a state-owned public newspaper that is distributed free of charge, and the others are commercially oriented, selling at around approximately US\$1.00. Only Mmegi and Daily News are dailies whereas all the others are weeklies. 


$\begin{array}{llccl}\text { Newspaper } & \text { Frequency } & \text { Circulation } & \text { Pages } & \text { Cost } \\ \text { Daily News } & \text { Daily } & 70,000 & 24 & \text { free } \\ \text { Mmegi } & \text { Monitor (Mondays) } & 11,000 & 20 & \text { P5.00 } \\ & \text { Mmegi (Midweek) } & 11,000 & 20 & \text { P5.00 } \\ & \text { Mmegi (Fridays) } & 22,000 & 52 & \text { P7.00 } \\ \text { Guardian } & \text { Fridays } & 19000 & 52 & \text { P8.00 } \\ \text { Midweek Sun } & \text { Wednesdays } & 17000 & 16 & \text { P5.50 } \\ \text { Gazette } & \text { Wednesdays } & 22,000 & 40 & \text { P8.00 } \\ \text { Sunday Standard } & \text { Sundays } & 30000 & 40 & \text { P7.00 }\end{array}$

Note: P8.50 = US\$1

Table 1: Profile of the main newspapers in Botswana.

There are also a few foreign newspapers, such as the Mail \& Guardian, Sowetan and Sunday Tribune and many others from neighboring countries, which are also popular in Botswana. The increase in the number of newspapers in Botswana has, naturally, led to stiff competition for audience members. This, coupled with uptake of digital technologies in the country has led many newsrooms to devise strategies to ensure that they maintain their market share while attempting to attract other audience members. One predictable development in this regard is that almost all newsrooms in Botswana have introduced online newspapers in addition to the traditional print publications. In view of this development in the newspaper landscape, this study sought answers to the following questions.

RQ 1. What constitutes the preferences and attitude of news audiences towards online newspapers compared to print newspapers in Botswana?

RQ 2. What factor(s) do audience members consider as important while accessing print and/or online news from Botswana?

\section{Traditional and online newspapers}

The Internet has impacted journalism practice as it has other areas of human endeavor. Lately, many newsrooms have taken advantage of the Internet's potential to create online news platforms that interest news audiences and extend their circulation. Today, there are many active online news sites and newspapers on the World Wide Web through which audiences read, discuss and share news content (Salwen et al. 2005). Studies suggest that the Internet has elicited changes in journalism as we know it; there are improvements in the ways journalists go about their tasks; improved relationships between newsrooms and audiences; and expansions of newsroom structures (Pavlik 2000). Scholars also see online newspapers as breathing new life into journalism, and re-engaging once skeptical and alienated audiences (Matheson 2004). And Pavlik (2000) places this changing character of journalism firmly in the corner of new technologies. 


\section{W. Lesitaokana and E. Akpabio}

Generally, expectations are that online newspapers complement print and offer extra services that include a convergence of media content, access to archives of news stories and fresh, up-to-date news and information (Bardoel and Deuze 2001; Gunter 2003; Paulussen 2004). Online newspapers also possess interactive, multimodal features (Kawamoto 2003; Matheson 2004; Paulussen 2004; Thurman 2008) and host a variety of content accessible through hyper-textual links that are created to primarily guide news audiences' interaction with online news content (Salwen et al. 2005). In this way, news audiences interact with online news content by contributing their viewpoints through user-generated polls, opinions, 'Questions and Answers', and message boards (Thurman 2008). This personal networking of news is occasionally referred to as 'networked', 'participatory' or 'citizen journalism' (Allan 2006; Bardoel and Deuze 2001; Thurman 2008; Xin 2011). Carpenter (2010) has singled out interactivity as the main factor that attracts news audiences to online news sites. Interactivity encompasses audiences' comments on news stories, blogging and other user-generated information and discussions of news content. This way, public communication has been made more interactive with many comments and exchanges (Sousa 2006). Similarly, Hujainen and Pietikainen (2004: 387) identify three discourses that are related to audience interactivity with online news: 'pick and choose', 'user in transition' and 'multi-voicing journalism'. 'Pick and chose' refers to the supply and demand side; 'user in transition' to the active audience members when they surf the Internet for news; and 'multi-voicing journalism' to the dialogic and interactive nature of online journalism.

Online newspapers also host news content that comprises various multimedia elements such as timelines, links, video and sound that make a news site a convergent creative environment (Verweij 2009). News convergence is driven by 'a series of conventions for presenting information' or 'for telling stories' (Gordon 2003: 70). Through the convergence of content, an online news story is told in various ways, and this allows news audiences to skim and scan through the content as they customize their online news consumption styles and habits (Hobbs 2008; Xiaoge 2008). Pavlik (2000) posits that multimedia news sites give the online news audience a sense of being present at news events. This suggests that while the Internet offers journalists various ways to tell a news story online, news audiences are then provided with many more options to understand the story. Due to the archiving of news content, audiences can consume news in their own time and at their own pace ensuring that it is not 'a mere producer-driven logic' but 'a matter of individual choice' (Bardoel 2002: 505). However, considering the pace at which content reaches the audience and its effect thereof, there are concerns that this immediacy is a death knell to traditional media and may spawn irresponsible reporting in the rush to be the first with the news (Mudhai 2011).

\section{Online journalism and news audiences}

The attractive and compelling features of online journalism touted by scholars have been described as a myth and out of touch with the reality on the ground. According to Domingo: 
The bottom line is the same: many professional and scholarly discourses tend to reproduce ideal models of what online journalism could be; taking them for granted as the path that news production on the Internet must walk. Empirical research has already offered evidence that the development of these ideals in online news sites tends to be limited. (2008: 680)

Scott (2005) contends that online journalism, instead of damming the downward spiral of traditional journalism away from its public service mission towards unbridled commercialism, has actually exacerbated the situation. This has been accomplished through the intentional actions of major news providers who have taken charge, so much so 'that the empty promise of a revitalized public sphere has given way to an even more tightly integrated oligopoly of commercial news networks' (Scott 2005: 92).

No wonder then that a number of out-of-work journalists pine for the good old days. Usher (2010) examined the farewell communications of online journalists, and noted that they reasserted traditional values, such as working in the public interest, remaining impartial, serving the voiceless, and providing a crucial link to democracy and healthy citizenship. The texts also revealed scholars' concern about the survival of these values in the new media world even though they 'may never truly have represented the truth about media discourse' (2010: 917). In terms of content for instance, online and traditional media have many areas of convergence, but also divergence with an emphasis on more local content for online sites and more depth and breadth for traditional newspapers (Maier 2010).

This raises questions about the relationship between online news sites vis-á-vis traditional print media. The literature generally offers no definite answers with some studies reporting displacement and others replacement (Gaskins and Jerit 2012). This made Nguyen and Western (2006) arrive at the inexorable conclusion that 'even if a displacement effect takes place, there will be no replacement (absolute displacement); traditional media will still exist to complement the internet in serving human beings' news and information needs'. Ahlers (2006) also cautions against the viewpoint that the competitive threat of the Internet will result in the demise of the print media noting that this lacks empirical support.

This study therefore, wades into the debate by providing a missing voice - an African perspective - to the persistent questions about news consumption patterns given the growth in media options (Maier 2010; Stempel et al. 2000) and the historical standpoint that the advent of new media serves to erode the audience base of older media (Gaskins and Jerit 2012).

\section{Methodology}

This study employed a mixed method approach that included an audience survey and focus group discussions with news audiences in Botswana. The advantages of a mixed method approach is that one method updates the results obtained from the 


\section{W. Lesitaokana and E. Akpabio}

other, consequently enhancing the credibility of the findings (Hesse-Biber and Leavy 2010). Whereas an audience survey was useful to describe associated demographics of news audiences and report the patterns of use of online newspapers in Botswana, focus group discussions offered further justifications as to why news audiences prefer and use online newspapers. The approaches undertaken in these methods are detailed in the next sections.

\section{Audience survey}

Utilizing multistage cluster sampling, 600 copies of the study questionnaire were administered face-to-face to potential news audiences in Francistown, Gaborone and Maun - which are some of the most populated centers in Botswana. Audience surveys are less expensive, allow for greater coverage and assist in obtaining views, attitudes, opinion and demographic data (Sarantakos 2005: 263). Justifiably, Gaborone, Maun and Francistown represent a varied scope of the study population since these three places are located about 450 kilometres from each other in the south, north-east and north-western part of Botswana. The study population included anyone aged 18 and above who lived in and around each of the three study locations, including the surrounding villages within a 50 kilometre radius. The survey questionnaire required participants to state their demographic characteristics and dispositions towards the media - online newspapers vis-à-vis print newspapers in Botswana.

\section{Focus group discussions}

Four focus group discussions with participants aged 18 and above were conducted in Gaborone. Focus group discussions are efficient and inexpensive since data is collected from several people at once (Cargan 2007), and during the discussion, the researcher is able to construct the meaning and also find a middle ground from the different comments within the context of a group (Byrne 2004; Tonkiss 2004). Two of the focus group discussions involved undergraduate students at the University of Botswana and Limkokwing University, and the other two were conducted amongst professionals in both the private sector and public service. These participants were chosen for this study because they have access to computers in colleges and workplaces. Overall, the focus group discussions in this study were useful in that they provided in-depth analysis of the statements made by respondents during the media audience survey. The topics that featured during the discussions sought to explore the following: Participants' benefits from reading online newspapers in Botswana as compared to print publications; decisions that prompted these benefits; participants' attitudes towards online newspapers; participants' news consumption styles, and also, the local news audiences' expectations about online newspapers in Botswana compared to print publications. The focus group participants were also required to discuss associated challenges that they experience when reading online newspapers in Botswana. 


\section{Findings}

\section{Newspaper audience survey}

Out of the 600 copies $(n=600)$ of the study questionnaire administered, 580 $(n=580)$ copies were retrieved, thus making a response rate of $96 \%$. While the same number of copies of the questionnaire $(n=200)$ were administered in each of the three study locations, $n=194$ were returned in Francistown, $n=197$ in Gaborone and $n=189$ in Maun. Although segmenting participants according to gender was never intended during the study, there were more female (55\%) than male respondents (45\%). Most respondents were employed in the public sector and quasi-governmental corporations and held secondary school certificates, diplomas and degrees, in that order.

An overwhelming majority (98.8\%) of the respondents stated that they read local newspapers. To disaggregate in terms of frequency; the majority of respondents read newspapers daily $(35.3 \%)$, weekly readers accounted for $28.5 \%$, twice-weekly readers accounted for $10.4 \%$, and those who read them 'sometimes' accounted for about a quarter of the respondents (25.8\%). A slight majority (51.2\%) of the study respondents indicated that they read online newspapers. Moreover, the overall attitudes to

\begin{tabular}{llrc} 
Demographics & Characteristics & $\boldsymbol{n}$ & $\%$ \\
\hline Gender & Male & 261 & 45 \\
Occupation & Female & 319 & 55 \\
& Business person & 24 & 4.1 \\
& Civil servant & 178 & 30.7 \\
& Pensioner & 1 & 0.2 \\
& Private sector employee & 141 & 24.3 \\
& Student & 185 & 31.9 \\
& Unemployed & 51 & 8.8 \\
Academic qualifications & Primary school certificate & 18 & 3 \\
& Junior sec. school certificate & 42 & 7 \\
& High school & 112 & 19.3 \\
& Post secondary certificate & 85 & 14.7 \\
& Diploma & 102 & 17.9 \\
& Degree & 194 & 33.4 \\
& Higher degree & 27 & 4.7 \\
Geographical Location & Francistown & 194 & 33.4 \\
& Gaborone & 189 & 34.6 \\
& Maun & &
\end{tabular}

Note: $N=580$

Table 2: Demographic characteristics of respondents. 


\begin{tabular}{lcc} 
Newspaper & \multicolumn{2}{c}{ Readership Pattern } \\
& Yes & No \\
\hline Daily News & $361(78 \%)$ & $100(22 \%)$ \\
Echo & $86(19 \%)$ & $375(81 \%)$ \\
Botswana Gazette & $192(42 \%)$ & $269(58 \%)$ \\
Botswana Guardian & $194(42 \%)$ & $267(58 \%)$ \\
Midweek Sun & $150(33 \%)$ & $311(67 \%)$ \\
Mmegi & $310(67 \%)$ & $151(33 \%)$ \\
Mmegi Monitor & $163(35 \%)$ & $298(65 \%)$ \\
Sunday Standard & $183(40 \%)$ & $278(60 \%)$ \\
The Voice & $367(80 \%)$ & $94(20 \%)$ \\
Tswana Times & $30(7 \%)$ & $431(93 \%)$
\end{tabular}

Note: $N=461$

Table 3: Print newspaper readership patterns.

online newspapers were positive $(t=5.138$; Mean=2.23), with a 5\% level of significance. In specific terms, the most widely read print newspapers were the weekly human-interest newspaper - The Voice (80\%), the Daily News (78\%) and a privately owned daily - Mmegi (67\%).

Almost the same pattern is discernible in terms of readership of online newspapers although with considerable less traffic. The three most visited websites were those of The Voice, Mmegi and the Daily News, in that order.

Respondents were also asked to compare online and print newspapers by indicating if they had positive, negative or neutral dispositions towards each type. In this regard, 'positive' signifies that they like online newspapers, 'negative' refers to their dislike towards online newspapers and 'neutral' to disinterest towards online newspapers. The indication on the level of agreement towards print newspapers was significantly

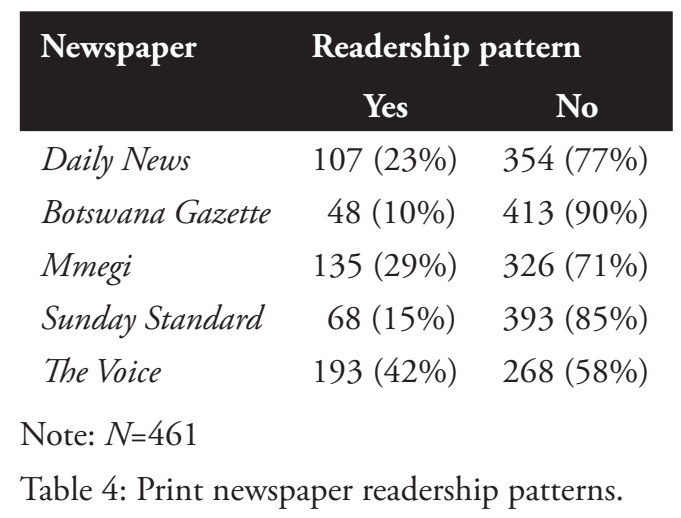




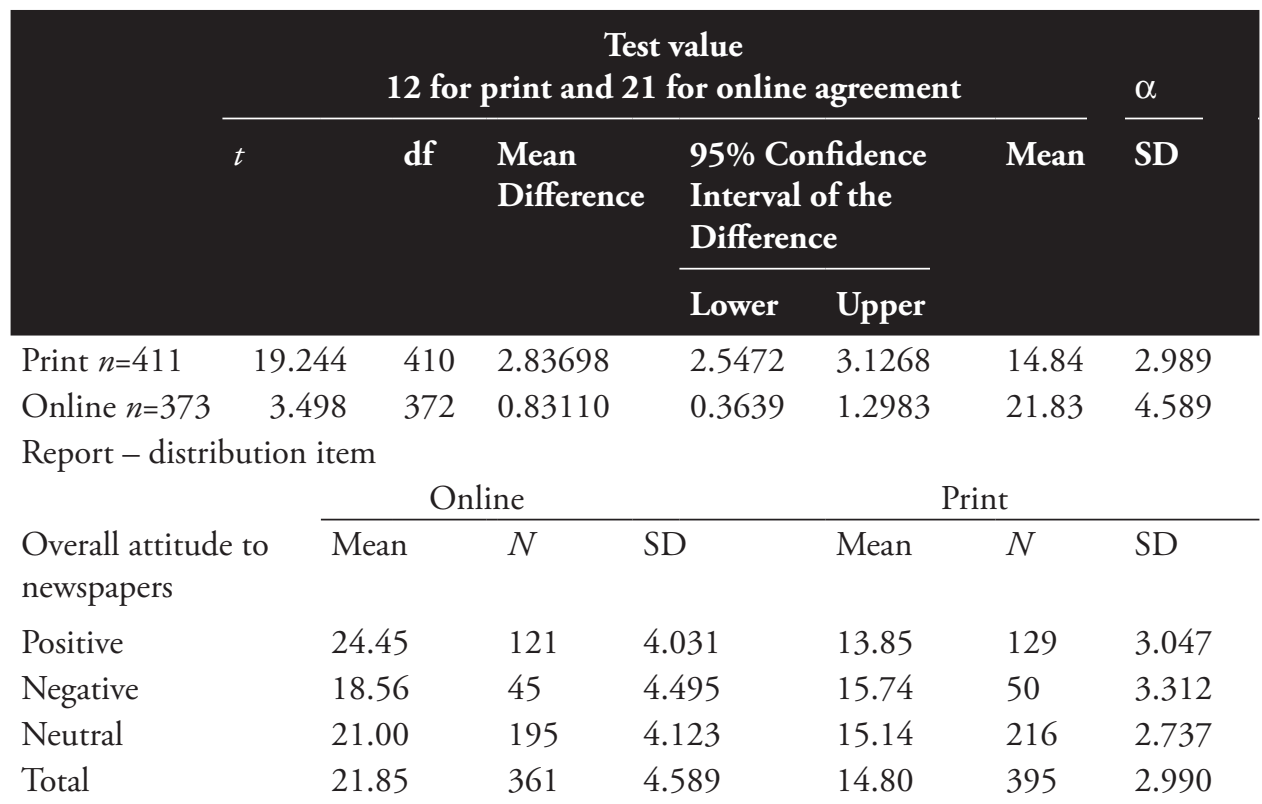

Table 5: One-sample test for respondents' disposition towards print and online newspapers.

higher than expected (Mean of 14.84>12) while that of online newspapers was almost neutral (Mean of 21.84>21.00).

Probing further in terms of factors informing this position, specifically looking at the indices of convenience, cost and layout; the findings indicate that cost and convenience were significant.

\begin{tabular}{|c|c|c|c|c|c|c|}
\hline $\begin{array}{l}\text { Reasons for } \\
\text { preference }\end{array}$ & & $\begin{array}{l}\text { Online } \\
\text { newspapers }\end{array}$ & $\begin{array}{l}\text { Print } \\
\text { newspapers }\end{array}$ & $\begin{array}{l}\text { Both } \\
\text { newspapers }\end{array}$ & $\chi^{2}$ & $p$-value \\
\hline \multirow[t]{2}{*}{ Cost } & Yes & 48 & 88 & 10 & 146 & \\
\hline & No & 33 & 250 & 12 & 295 & \\
\hline Total & & 81 & 338 & 22 & 441 & \\
\hline$\chi^{2}(2, N=441)$ & & & & & 34.162 & 0.000 \\
\hline \multirow[t]{2}{*}{ Convenience } & Yes & 52 & 156 & 18 & 226 & \\
\hline & No & 29 & 182 & 4 & 215 & \\
\hline Total & & 81 & 338 & 22 & 441 & \\
\hline$\chi^{2}(2, N=441)$ & & & & & 17.176 & 0.000 \\
\hline \multirow[t]{2}{*}{ Layout } & Yes & 8 & 75 & 5 & 88 & \\
\hline & No & 73 & 263 & 17 & 253 & \\
\hline Total & & 81 & 338 & 22 & 441 & \\
\hline$\chi^{2}(2, N=441)$ & & & & & 6.313 & 0.043 \\
\hline
\end{tabular}

Table 6: Factors impacting preferences between print and online newspapers. 


\section{Focus group discussions}

Similar to the findings from the audience survey, the focus group discussants also concurred on three main issues with regard to online newspapers: that they are accessed free of charge in Botswana, are convenient to read and are easily accessible at their colleges and workplaces. Specifically, the student participants stated the following: that they commonly read online newspapers, they access online newspapers while multi-tasking at colleges and they are loyal readers of online newspapers The Voice, Mmegi and the Sunday Standard. They mentioned that they preferred online newspapers compared to the print version because online newspapers allow them to multitask, such as listening to music, chatting with friends online and even studying while reading them.

The participants also pointed out that both Mmegi and the Sunday Standard are highly educative and are good online sources of information since, generally, with other sources there is limited online information about issues in Botswana. As for The Voice, focus group participants' interests lay in its tabloid-style reporting. Even though the state-owned Botswana Daily News has the highest circulation in the country with a print run of 70,000 copies daily and is distributed free of charge nationwide, the study's student participants mentioned that they still have problems accessing the newspaper. Therefore, an online copy of the Daily News becomes a ready alternative. One of the discussants remarked: 'Perhaps the Daily News print copy is only reserved for government officials and people in civic offices. We students hardly access it, except when we go online to read it'.

As it turned out, the focus group discussants concurred that they do not have adequate Internet access outside their colleges, except through smart phones, which they prefer to use for social networking instead of for reading online newspapers. According to discussants there are many print newspapers in Botswana, therefore buying a copy of each daily or weekly is costly, hence they prefer online newspapers instead.

Interestingly, the civil servants and professionals in Botswana indicated that they preferred online newspapers during office hours while they reserved print copies for after hours. According to the participants, this is because they are prohibited from reading print newspapers during office hours, and for most of them it is only at workplaces where they have adequate Internet availability to read online newspapers. One of the discussants explained:

The Daily News is sent to our offices from Monday to Friday but I am still afraid to be seen reading it during office hours, hence I go online to read it free of charge along with other local newspapers.

Although all the focus group participants have favorable attitudes towards online newspapers, they are disappointed that online newspapers in Botswana do not have exciting multimedia content and highly interactive hyperlinks that provide more 
information on stories compared to other international online news sites, such as the BBC, CNN and the New York Times. Despite the limited interactivity in some local online newspapers, the websites of The Voice and Mmegi newspapers provide minimal interactivity. Overall, the focus group participants concurred that they would like to see online newspapers in Botswana produced with more interactive, colorful and attractive multimedia content, and also featuring interactive hyperlinks that would allow them to post comments and engage more with the news through online conversations and commentaries.

\section{Discussion}

Print publications are undergoing a difficult time in the face of the inroad of online publications and their various features, which make for greater interaction and sharing of content amongst others. No wonder the spokesperson for the UK's Guardian newspaper, which has a declining print product and a thriving digital one with 34 million unique visitors worldwide, noted that 'the print business is in decline, and nothing is going to reverse that'. ${ }^{2}$ While there is no unanimity of opinion by scholars on whether online publications displace or supplement traditional print newspapers, this study provides empirical proof that print newspapers remain the most preferred over and above their online counterparts in Botswana.

There is no doubt, going by the findings of this study, that online newspapers are making a lot of inroads but they are yet to overtake readership of print products. Also, it is interesting to note that in Botswana almost the same pattern of readership of print newspapers is reflected in the online environment, with just a few changes: Mmegi upstages the Daily News when it comes to online preferences even though it is ranked number three regarding audience members who read print publications.

Contemporary studies of journalism and new media indicate that news audiences prefer to read online newspapers because they are generally interactive, host multimedia content and publish news that is immediate (Kawamoto 2003; Matheson 2004; Paulussen 2004; Thurman 2008). In contrast, Botswana news audiences like online newspapers mainly because they are free (no pay wall); accessible at their colleges and places of work; and convenient to access while performing other tasks.

This study clearly shows that the interest of audience members in online newspaper is being driven by cost and convenience and not the layout of the publications. To disaggregate the data, the cost of print newspapers was a huge put off. It seems that audience members still prefer free content that is available in the Botswana online environment. As we have already highlighted above, with the exception of the Botswana Daily News, all print newspapers in Botswana are available for sale at newsstands, and as a result online newspapers remain an option since they are freely available. The Voice's (whose print and online version is ranked number one) main selling point is its appeal to the lowest common denominator and this seems to resonate with audience members. 
Our findings also indicate that news audiences' consumption patterns in Botswana remain skewed towards the more familiar print edition. This is because most online newspapers in Botswana are not highly interactive, exciting or interesting since they are replicas of the print copies, and do not have multimedia content; a point stressed by Domingo (2008). Sadly, the focus on the online effort in many local newsrooms is the re-distribution of the print copies through the newspapers' website. In spite of this constraint, limited instances of participatory journalism can be observed in online newspapers such as The Voice and Mmegi.

However, study participants are of the view that they still find it difficult to navigate for stories in online newspapers. Consequently, participants in this study are concerned that this under-development of online journalism in the country hampers their online participation, such as not being able to post comments and viewpoints on issues that are reported in the local media. This limits interactivity to only 'e-mail to the editor'; a version of which has always been practiced with print newspapers. However, Schultz (1999) observed that interactivity should transcend letters to the editors, and trigger threads of messages as part of reactions to news stories between newsreaders and newsroom staff. Thurman (2008) concurs and adds that involving news audiences in this way may help by significantly attracting more audience members and subsequently impacting online newsreaders' attitudes to online newspapers.

Internet connectivity remains inadequate in many parts of Botswana. ${ }^{3}$ Presumably, this has remained a constant challenge to many potential news audiences in rural areas and consequently has affected access to online publications. Whereas indications are that online journalism is experiencing growth in many regions across the globe, in Botswana, this growth is constantly impeded by inadequate Internet connections in many parts of the country. Nevertheless, indications are that the introduction of online newspapers has breathed new life into journalism by fostering greater access to news stories far beyond the limited geographic reach of print circulations. This became evident with survey respondents in Maun and Francistown, since almost all the newspapers in Botswana are printed and published from Gaborone - the capital city - and it would take about two days before they arrive in Maun and Francistown.

\section{Conclusion}

This study makes an important contribution to the literature by providing an African perspective to the debate on new media versus traditional media. Our findings also established that while new media technologies continue to influence new trends and practices in journalism globally, audience experiences with these technologies differ from country to country. In the specific instance of Botswana, traditional newspapers still have a slight edge over their online counterparts principally because online newspapers do not have the required interactive and multimedia elements.

At issue also is the poor level of Internet access. As a consequence, students and workers use the time at campus and in their offices to access online newspapers. But after office hours, workers revert to traditional newspapers because they are now able 
to read such without hindrance unlike in the work environment where their bosses frown on reading of newspapers. Students, on the other hand, do not have access outside of the campus environment, even though they would love to have access to the free government-owned newspaper Daily News. An incidental finding of the study is that students have been neglected in the circulation of Daily News and this important demographic should be catered for.

There are, however, a number of limitations to this study. We did not find out what devices are used to access online content, especially now that smart phones and tablets seem to be the in-thing. It is possible that in the future if there is a greater uptake of smart phones and tablets in Africa, the market for and access to traditional print publications may shrink further. Not within the ambit of the present study was finding out if respondents accessed international online news sites. Studies probing these angles would help throw more light on Botswana audience news seeking and consumption behaviors. Other researchers may also wish to obtain the views of Botswana media managers on the online newspaper threats and how they are striving to balance their print and online assets. Other studies may also consider direct comparisons between print and online newspapers through content analysis.

\section{Notes}

1. http://www.thuto.org/ubh/bw/bhp15.htm, accessed 1 October 2010.

2. http://adage.com/article/digital/daily-beast-eatnewsweek/237894/?utm_ source=mediaworks\&utm_medium=newsletter\&utm_campaign=adage, accessed 30 October 2012.

3. http://www.gazettebw.com/index.php?option=com_content\&view=article\&id=5647:botsw anas-internet-connectivity-still-low-\&catid=13:business\&Itemid=2, accessed 3 March 2010.

\section{References}

Ahlers, D. (2006), 'News consumption and the new electronic media', The Harvard International Journal of Press/Politics, 11: 1, pp. 29-52.

Allan, S. (2006), Online News: Journalism and the Internet, London: Open University Press.

Atton, C. and Mabweazara, H. (2011), 'New media and journalism practice in Africa: An agenda for research', Journalism, 12: 6, pp. 667-73.

Bardoel, J. (2002), 'The Internet, journalism and public communication policies', International Communication Gazette, 64: 5, pp. 501-11.

Bardoel, J. and Deuze, M. (2001), 'Network journalism: Converging competencies of media professionals and professionalism', Australian Journalism Review, 23: 2, pp. 91-103.

Byrne, B. (2004), 'Qualitative interviewing', in C. Seale (ed.), Researching Society and Culture, London: Sage Publications, pp. 179-92.

Cargan, L. (2007), Doing Social Research, Lanham, Maryland: Rowman \& Littlefield Publishers Inc.

Carpenter, S. (2010), 'A study of content diversity in online citizen journalism and online newspaper articles', New Media \& Society, 12: 7, pp. 1064-84.

Cottle, S. (2000), 'Rethinking news access', Journalism Studies, 1: 3, pp. 427-48. 
Davis, S. (2000), 'Public journalism: The case against', Journalism Studies, 1: 4, pp. 686-689.

Deuze, M. (1999), 'Journalism and the Web', International Communication Gazette, 61: 5, pp. 373-90.

Domingo, D. (2008), 'Interactivity in the daily routines of online newsrooms: Dealing with an uncomfortable myth', Journal of Computer-Mediated Communication, 13: 3, pp. 680-704.

Fahy, D. and Nisbet, M. C. (2011), 'The science journalist online: Shifting roles and emerging practices', Journalism, 12: 7, pp. 778-93.

Gaskins, B. and Jerit, J. (2012), 'Internet news: Is it a replacement for traditional media outlets?', The International Journal of Press/Politics, 17: 2, pp. 190-213.

Gordon, R. (2003), 'The meaning and implications of convergence', in K. Kawamoto (ed.), Digital Journalism: Emerging Media and the Changing Horizons of Journalism, Lanham: Rowman \& Littlefield Publishers Inc., pp. 57-74.

Granado, A. (2011), 'Slaves to journals, serfs to the web: The use of the Internet in newsgathering among European science journalists', Journalism, 12: 7, pp. 794-813.

Gunter, B. (2003), News and the Net, New York: Lawrence Erlbaum Associates Inc.

Hesse-Biber, S. N. and Leavy, P. (2010), The Practice of Qualitative Research, 2nd ed., Thousand Oaks: Sage.

Hobbs, D. (2008), 'Gen Y journalists', Ejournalist, 8: 2, pp. 23-42.

Hujanen, J. and Pietikainen, S. (2004), 'Interactive uses of journalism: Crossing between technological potential and young people's news-using practices', New Media \& Society, 6: 3, pp. 383-401.

Kawamoto, K. (2003), 'Digital journalism: Emerging media and the changing horizons of journalism', in K. Kawamoto (ed.), Digital Journalism, Lanham: Rowman \& Littlefield Publishers Inc., pp. 1-29.

Kolodzy, J. (2006), Convergence Journalism: Writing and Reporting across the News Media, Lanham: Rowman \& Littlefield.

Lowrey, W. (2006), 'Mapping the journalism-blogging relationship', Journalism, 7: 4, pp. 477-500.

Maier, S. (2010), 'All the news fit to post? Comparing news content on the Web to newspapers, television, and radio', Journalism \& Mass Communication Quarterly, 87: 3-4, pp. 548-562.

Matheson, D. (2004), 'Weblogs and the epistemology of the news: Some trends in online journalism', New Media \& Society, 6: 4, pp. 443-68.

Mudhai, O. F. (2011), 'Immediacy and openness in a digital Africa: Networked-convergent journalisms in Kenya', Journalism, 12: 6, pp. 674-91.

Nguyen, A. and Western, M. (2006), 'The complementary relationship between the Internet and traditional mass media: The case of online news and information', Information Research, 11: 3, pp. 1-18.

Paulussen, S. (2004), 'Online news production in Flanders: How Flemish online journalists perceive and explore the Internet's potential', Journal of Computer Mediated Communication, 9: 4, pp. 24-41.

Pavlik, J. (2000), 'The impact of technology on journalism', Journalism Studies, 1: 2, pp. 229-37.

Rantao, P. (1996), 'The role of the media in promoting participatory politics in Botswana', in M. Leepile (ed.), Botswana's Media and Democracy, Gaborone: Mmegi Publishing House, pp. 3-20.

Salwen, M. B., Garrison, B. and Driscoll, P. D. (2005), Online News and the Public, Lawrence Erlbaum. 
Sarantakos, S. (2005), Social Research, Hampshire: Palgrave Macmillan.

Schultz, T. (1999), 'Interactive options in online journalism: A content analysis of 100 U.S. newspapers', Journal of Computer-Mediated Communication, 5: 1, pp. 1-20.

Scott, B. (2005), 'A contemporary history of digital journalism', Television \& New Media, 6: 1 , pp. 89-126.

Sousa, H. (2006), 'Information technologies, social change and the future', European Journal of Communication, 21: 3, pp. 373-87.

Stempel III, G. H., Hargrove, T. and Bernt, J. P. (2000), 'Relation of growth of use of the Internet to changes in media use from 1995 to 1999', Journalism and Mass Communication Quarterly, 77: 1, pp. 71-79.

Thorson, E. (2008), 'Changing patterns of news consumption and participation', Information, Communication \& Society, 11: 4, pp. 473-89.

Thurman, N. (2008), 'Forums for citizen journalists? Adoption of user generated content initiatives by online news media', New Media \& Society, 10: 1, pp. 139-57.

Tonkiss, F. (2004), 'Using focus groups', in C. Seale (ed.), Researching Society and Culture, London: Sage Publications, pp. 193-206.

Usher, N. (2010), 'Goodbye to the news: How out-of-work journalists assess enduring news values and the new media landscape', New Media \& Society, 12: 6, pp. 911-928.

Verweij, P. (2009), 'Making convergence work in the newsroom', Convergence: The International Journal of Research into New Media Technologies, 15: 1, pp. 75-87.

Xiaoge, X. (2008), 'Engaging and empowering news audiences online: A feature analysis of nine Asian news websites', Ejournalist, 8: 1, pp. 35-53.

Xin, X. (2011), 'Web 2.0, Citizen journalism and social justice in China', in G. Meikle and G. Redden (eds), News Online: Transformations and Continuities, Basingstoke: Palgrave Macmillan, pp. 178-194.

\section{Suggested Citation}

Lesitaokana, W. and Akpabio, E. (2014), 'Traditional versus online newspapers: The perspective of news audiences in Botswana', Journal of Applied Journalism \& Media Studies 3:

2, pp. 209-224, doi: 10.1386/ajms.3.2.209_1

\section{Note on Contributors}

William O Lesitaokana is a Digital Media lecturer at the University of Botswana where he has taught undergraduate courses in media production and new media theories. He has a number of scholarly publications to his name in referred journals. William's research interests include the media in Botswana, new media technologies and youth cultures, and online journalism. Currently, he is studying for a Ph.D. at Griffith University in Australia.

Contact: University of Botswana, Private Bag 00703, Gaborone, Botswana.

E-mail: lesitaokana@gmail.com

Eno Akpabio is a Professor of Journalism and Mass Communication at the University of Namibia. Prior to this appointment, he served as Associate Professor in the Department of Media Studies, University of Botswana. Professor Akpabio has a number of publications to his name, including two books (African Communications Systems: An Introductory Text and Writing 
to Win Hearts and Minds), many chapters in books and numerous articles in learned journals. His research interests span applied and indigenous communication as well as popular culture.

Contact: University of Namibia, Private Bag 13301, Windhoek, Namibia.

E-mail: enoakpabio@gmail.com

William Lesitaokana and Eno Akpabio have asserted their right under the Copyright, Designs and Patents Act, 1988, to be identified as the authors of this work in the format that was submitted to Intellect Ltd. 